\title{
Nazis by Kraut: A Playful Application of Moral Self-Licensing
}

\author{
Claude Messner, Adrian Brügger \\ Institute of Consumer Behavior, University of Bern, Bern, Switzerland \\ Email: claude.messner@imu.unibe.ch
}

Received 4 June 2015; accepted 17 July 2015; published 22 July 2015

Copyright (C) 2015 by authors and Scientific Research Publishing Inc.

This work is licensed under the Creative Commons Attribution International License (CC BY). http://creativecommons.org/licenses/by/4.0/

(c) (i) Open Access

\begin{abstract}
Doing something moral gives one a license to do something immoral. This form of moral compensation is called "moral self-licensing". Interestingly, the moral behavior can take place in another domain than the subsequent immoral behavior. For example, buying eco-friendly products gives one a license to steal. This article is based on the idea that a healthy diet has a moral dimension. As a consequence, consuming a healthy product should give one a license for immoral behavior. This research supports this hypothesis on a playful study. This study shows that drinking sauerkraut juice contributes to a stronger support of Nazi-esque right wing ideology than drinking either nothing or a less-healthy beverage (Nestea).
\end{abstract}

\section{Keywords}

\section{Moral Self-Licensing, Prejudice, Stereotypes, Nutrition, Health}

\section{Introduction}

Sauerkraut juice contains three times as much vitamin $\mathrm{C}$ as orange juice. It is rich in fiber, and it is easily digestible. Sauerkraut juice is, in other words, very healthy. Consuming such a healthy product can have an effect on further consumption (Finkelstein \& Fishbach, 2010). On one hand, it could be interpreted as a signal that one has committed to a healthy diet and would continue to consume healthy products. Or on the other hand, it could be interpreted to mean that one has already put sufficient effort toward one's health. And in this case, consuming a healthy product gives one a license to compensate, such as by eating something less healthy. However, consuming healthy products gives one a license for other compensatory behaviors as well.

In particular, we argue that the consumption of a healthy drink has a moral dimension and therefore initiates the same compensatory mechanism as other moral behaviors. This assumption is based on the observation that a moral behavior can give one a license to do something immoral. This effect is called "moral self-licensing" 
(Merritt, Effron, \& Monin, 2010; Miller \& Effron, 2010; Monin \& Miller, 2001). One theoretical explanation for this effect is based on the metaphor of a moral bank account (Miller \& Effron, 2010; Monin \& Miller, 2001). We earn moral credits for moral behavior, which then give us a license to do something immoral. For example, remembering past moral behavior, like volunteering at a soup kitchen, increases one's willingness to do something immoral, like cheating (Jordan, Mullen, \& Murnighan, 2011). More importantly, for the present study, moral self-licensing also applies to decisions that are less directly related to morality, such as consumption decisions. For instance, working increases the tendency to buy a luxury product (Khan \& Dhar, 2006), and buying organic products increases the likelihood of cheating (Mazar \& Zhong, 2010). The aim of this article is to demonstrate that consuming something healthy could give one a license to express immoral opinions more openly.

\subsection{Morality and Food Choices}

Food choices are a domain where moral self-licensing may occur. Several lines of reasoning suggest that healthy nutrition has a moral dimension. Nutrition and food choices are tinged by morality because society holds individuals morally accountable for a healthy lifestyle (Brown, 2013). Furthermore, it is common to judge the morality of others based on what and how much they eat (Vartanian, Herman, \& Polivy, 2007). For instance, people who eat non-fattening foods are considered more moral than people who eat fattening foods (Stein \& Nemeroff, 1995); oatmeal eaters are perceived as more moral than pie eaters (Oakes \& Slotterback, 2004). Consistent with these theoretical links between morality and food choices, moral behavior is found to give one a license to eat less healthy products (Weibel, Messner, \& Brügger, 2014). The goal of this paper is to demonstrate the reverse effect. This article demonstrates that consuming something healthy gives one a license to hold immoral attitudes. More precisely, this article shows that drinking sauerkraut juice increases endorsement statements expressing anti-Semitism, derogating other nations and religions, or devaluing the humanity of others.

\subsection{Pre-Test}

We conducted a short pre-test and asked 128 Swiss student participants by an online questionnaire which person is more moral, a person who drinks sauerkraut juice or a person who drinks Nestea. In line with the reasoning presented in our paper, $70 \%$ of participants indicated that the person who drinks sauerkraut juice is more moral than the person who drinks Nestea, $\chi^{2}(1,128)=21.75, p<0.0001$.

In addition, we validated our dependent variable. The dependent variable consists of nine statements. The statements are actually typical topics currently being discussed in Switzerland that are consistent with a right wing ideology: Devaluing other cultures (e.g., "seeing a woman wearing a burqa makes me uncomfortable"), devaluing other nations (e.g., "foreign nationals who live in Switzerland are a burden on the social system"), affirming anti-Semitism (e.g., "due to the politics of Israel, I can understand a resentment toward Jews"), devaluing the humanity of others (e.g., the claim that "all public buildings should be adapted for people with disabilities is, in my opinion, overstated"). The appendix contains all nine statements. We asked the 128 participants to rate on a six point scale how politically left (1) or right (6) and how moral (1) or immoral (6) a person is who agrees to one of the nine statements of our dependent variable. All statements were assessed as more right than the midpoint (3.5), all $t s(127)>5.47$, all $p s<0.0001$, all $d s>0.97$. In addition, all nine statements were evaluated as immoral. The statement with the smallest immorality was "Seeing a woman wearing a burqa makes me uncomfortable", $t(127)=2.25, p=0.025, d=.4$. The other eight statements were assessed as clearly more immoral than the midpoint $(3,5)$, all $t s(127)>6.39$, all $p s,<0.0001, d>1.13$.

\section{Method}

\subsection{Participants and Design}

One hundred fifty-one students from a Swiss university were recruited for a study on consumer behavior. As remuneration, participants received a voucher of approximately $\$ 6$ for the university's cafeteria. Forty participants had non-Swiss citizenship. They were excluded from the analyses because their nationalistic bias was not necessarily in favor of Switzerland. Of the remaining 111 participants, 65 were female $\left(M_{\text {(AGE) }}=23.31, S D_{(\mathrm{AGE})}=\right.$ 3.69). The experiment employed a one-factorial design with three conditions. A third of the participants drank sauerkraut juice, a third drank Nestea, and a third drank nothing. Each participant was randomly assigned to one condition. 


\subsection{Procedure and Material}

Participants were tested individually. For participants who drank sauerkraut juice or Nestea, the questionnaire consisted of two parts, and they received a cup with $100 \mathrm{ml}$ of the beverage. The first part of the questionnaire contained five questions concerning a product test (appearance, smell, taste, health, and frequency of consumption). While four of the questions were included solely to make it plausible that it was a real product test, the health questions revealed whether the participants expected that drinking sauerkraut juice was healthy. Participants were asked about how they expected drinking sauerkraut juice to affect their health on a 10-point scale ( 1 = very negative; 10 = very positive). This question served as a manipulation check. The second part of the questionnaire measured their right wing attitudes and demographics. To gauge their adherence to right wing attitudes, participants were asked how much they agreed with nine statements on a 10-point scale $(1=$ oppose completely; $10=$ totally agree). The appendix contains all nine statements. Because of the high correlation of these statements, we averaged them to one "right wing attitude scale" (Cronbach $\alpha=0.74$ ).

One of the demographic variables that we assessed is political orientation. Participants assessed their political orientation on a 10-point scale from left (1) to right (10). The three treatment groups do not differ in their political orientation $\left(M_{\text {Sauerkraut }}=4.5, S D_{\text {Sauerkraut }}=1.81, M_{\text {Nestea }}=4.36, S D_{\text {Nestea }}=2.11, M_{\text {no beverage }}=3.88, S D_{\text {no beverage }}=\right.$ 1.6), $F(2,106)=1.05, p=0.35$. The endorsement of each of the nine statements of the dependent variable correlates with political orientation between $r=0.24, p=0.01$ and $r=0.69 . p<0.0001$. Importantly, our dependent variable (i.e., the arithmetic mean of all items) also correlates with participants' political orientation: The more right wing the participants assessed themselves the higher the endorsement of the right wing ideology, $r=0.67$, $p<0.0001$.

\subsection{Ethics Statement}

When conducting the research, we followed ethical standards of the American Psychological Association ("Ethical Principles of Psychologists and Code of Conduct" 2012), and of the local ethic committee (Kantonale Ethikkommission Bern, 2011). All participants provided their written informed consent.

\section{Results}

\subsection{Manipulation Check}

Sauerkraut juice was perceived as healthy. Participants believed that drinking sauerkraut juice would have a more positive effect on their health $(M=7.03, S D=1.39)$ than drinking Nestea $(M=3, S D=1.04), t(77)=$ 14.64, $p<0.0001, d=3.28$. The evaluation of sauerkraut juice was more positive than the midpoint of the scale (5.5), $t(38)=6.88, p<0.0001, d=2.23$, which suggests that sauerkraut juice was perceived as healthy.

\subsection{Endorsement of Right Wing Ideology}

A one-factorial ANOVA revealed that the three beverage conditions differ in their influence on the endorsement of the right wing statements, $F(2,108)=3.16, p=0.047$. In line with our prediction, participants agreed more strongly with right wing statements after drinking sauerkraut juice $(M=4.46, S D=1.43)$ than participants in the control group, who drank nothing $(M=3.73, S D=1.39), t(69)=2.15, p=0.02, d=0.52$, or those who drank Nestea $(M=3.82, S D=1.25), t(77)=2.09, p=0.04, d=0.48$ (Figure 1 ).

\subsection{Mediation Analysis}

Sauerkraut juice differs from Nestea not only in healthiness but also in taste. Sauerkraut juice tastes worse $(M=$ $2.95, S D=1.75)$ than Nestea $(M=7.18, S D=1.81), t(77)=10.56 p<0.0001, d=2.38$; and sauerkraut juice smells less pleasant $(M=3.33, S D=1.49)$ than Nestea $(M=6.78, S D=1.66), t(77)=9.69 p<0.0001, d=2.19$. This confound allows alternative explanations of the results. On one hand, consuming unpleasant products could decrease one's self-control (Hagger, Wood, Stiff, \& Chatzisarantis, 2010) and thus encourage antisocial attitudes (Hagger et al., 2010). On the other hand, the consumption of unpleasant-tasting sauerkraut juice could induce a more negative mood than the consumption of Nestea. Negative mood could increase the use of stereotypes as well (Esses, Haddock, \& Zanna, 1994; Forgas, 1995). Finally, there is evidence of a direct link between unplea- 


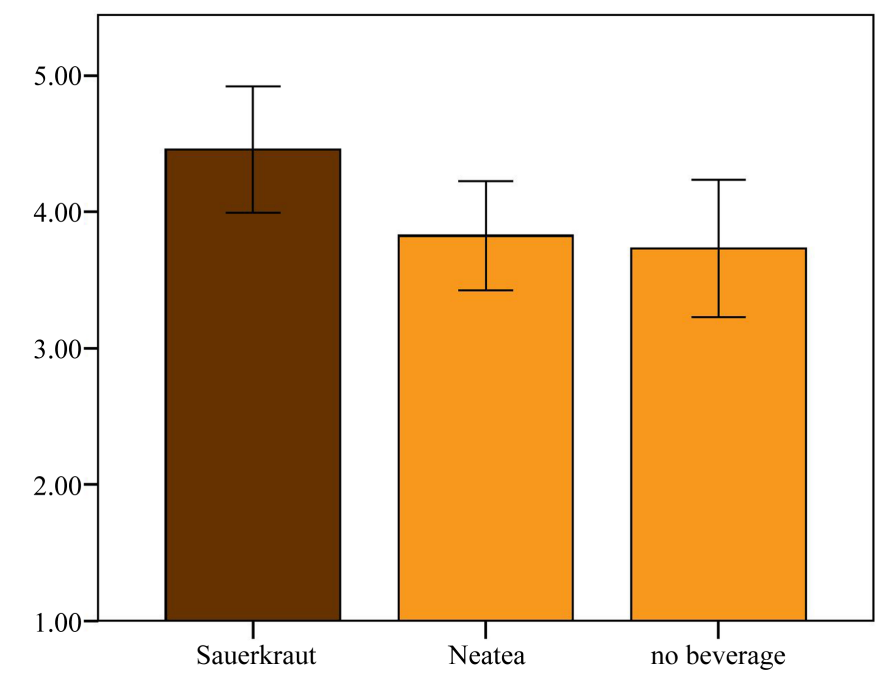

Figure 1. Endorsement of right wing statements as a function of consumed beverages. Participants who consumed sauerkraut juice agreed more with right wing statements than those who consumed Nestea or no beverage.

sant tastes and immoral judgments (Chapman, Kim, Susskind, \& Anderson, 2009; Eskine, Kacinik, \& Prinz, 2011; Eskine, Kacinik, \& Webster, 2012). All those alternative explanations are based on the unpleasant experiences of the consumption and not on the healthiness of the beverages. Therefore, we conducted three mediation analyses and tested whether taste, smell, or healthiness mediates the influence on the right wing ideology.

Because the participants in the control condition without any beverages could not offer opinions on taste, smell, or heath, the mediation analysis refers only to the two conditions where beverages were consumed. We coded sauerkraut juice with 1 and Nestea with -1 . All three mediation analyses refer to the influence of drinking Nestea or sauerkraut juice on the endorsement of the right wing statements $(\beta=0.23, p=0.04)$. The mediation analyses revealed that it is more likely that healthiness caused the change in right wing ideology than the unpleasant experience. We used the SPSS script "Process" (Hayes, 2013; http://www.processmacro.org) to analyze the mediations (model 4) by drawing 10,000 samples for bootstrapping and testing the indirect effects on a 90\% confidence interval. The expectation that consuming the beverage improves health mediates the effect of right wing ideology (point estimate $=0.34, C I=0.05$ to 0.63 ), but neither taste (point estimate $=0.004, C I=-0.19$ to 0.21 ) nor smell (point estimate $=-0.04, C I=-0.22$ to 0.15 ) mediates right wing ideology (for more details see Table 1).

\section{Discussion}

During the Second World War, the English used the word "Krauts" as a derogatory way of referring to Germans. This usage derives from the stereotype of the sauerkraut-eating German. This research shows that, ironically, drinking sauerkraut juice is associated with stronger endorsement of right-wing ideology than consumption of a comparison beverage. This association is attributable to the perceived healthiness of sauerkraut juice. Eating a healthy diet has a moral dimension (Vartanian et al., 2007). Eating something healthy, therefore, gives one a license to express immoral attitudes.

We assessed endorsement of attitudes relevant to contemporary debates in Switzerland (derogation of other nations or religions, anti-Semitism, and devaluation of the humanity of others), which overlap with Nazi ideology. Some of statements we used related to issues which had been subject to public votes in Switzerland shortly before these data were collected, for example the 2013 vote on banning the wearing of burqas within an area of Switzerland. Other statements related to issues raised by right-wing political parties, for example, the proportion of German professors at Swiss universities. We only investigated a subset of right-wing positions, namely those which are consistent with Nazi ideology, so we cannot be certain that consumption of sauerkraut juice would be associated with stronger endorsement of all right-wing positions. 
Table 1. Influence of drinking sauerkraut juice on right wing ideology.

\begin{tabular}{|c|c|c|c|c|c|c|c|c|}
\hline \multirow{2}{*}{ Mediator } & \multicolumn{2}{|c|}{ a } & \multicolumn{2}{|c|}{$\mathrm{b}$} & \multicolumn{2}{|c|}{$c^{\prime}$} & \multicolumn{2}{|c|}{ Indirect effect } \\
\hline & $\beta$ & $p$ & $\beta$ & $p$ & $\beta$ & $p$ & $\beta$ & $C I$ \\
\hline Health & 0.86 & $<0.0001$ & 0.39 & 0.07 & -0.10 & 0.62 & 0.34 & 0.05 to 0.63 \\
\hline Smell & -0.74 & $<0.0001$ & 0.05 & 0.75 & 0.27 & 0.10 & -0.04 & -0.22 to 0.15 \\
\hline Taste & -0.77 & $<0.0001$ & -0.01 & 0.98 & 0.23 & 0.20 & 0.004 & -0.19 to 0.21 \\
\hline
\end{tabular}

Note: three mediation analyses demonstrate that the influence of drinking sauerkraut juice on right wing ideology (c: $\beta=0.23, p=0.04$ ) is mediated by an expected influence on health but not by the smell or taste of the beverages.

\subsection{What Caused the Effect?}

Moral self-licensing predicts that any kind of moral behavior can give one a license to undertake an immoral behavior, even in another domain (Merritt et al., 2010; Miller \& Effron, 2010). There are several alternative explanations as to why consuming sauerkraut juice could influence right wing ideology. Consuming sauerkraut juice is an unpleasant experience. However, neither smell nor taste correlate with right wing ideology, and they do not mediate the influence of drinking sauerkraut juice on right wing ideology.

In contrast to the alternative explanations, we base our arguments of moral self-licensing on the moral aspects of improving one's health. Healthiness mediates the influence of drinking sauerkraut juice on right wing ideology on a $90 \%$ confidence interval. This is evidence that healthiness is involved in the effect.

\subsection{Does Healthiness Increase Immoral Attitudes?}

The tendency to support right wing ideology more strongly after drinking a healthy drink does not mean that people who care more about their health are less moral or identify more with a right wing ideology. There are many ways to balance one's moral bank account. Prosocial behaviors may carry more moral credit than healthy nutrition. The concept of a moral bank account also implies that it is harder for people with high nutritional standards to earn moral credit by eating healthily; it is easier to earn credit in domains where one's standards are lower. Attitude strength moderates moral self-licensing (Effron et al., 2009) so it is unlikely that people feel they earn a license for moral compensation through moral behavior in a domain where they hold strong attitudes.

\subsection{Limitations and Recommendations for Future Research}

Measuring or manipulating nutritional standards would allow testing if the strength of attitudes moderates this moral self-licensing effect. A further improvement of this study would be another manipulation of the healthiness of the beverages. Instead of using healthy and unhealthy products, one could frame one product as healthy or unhealthy. For example, an orange juice has healthy components (vitamin C, fiber) and unhealthy (sugar, chemicals). This would reduce the confounding factors in the manipulation and reduce the plausibility of alternative explanations. Finally, we constructed a measure of Nazi-esque attitude. This measure corresponds to contemporary debates in Switzerland, but a validated measure of ethnocentrism or racism (e.g. modern racism scale) would give stronger evidence.

\subsection{Contribution}

The message of this article is not an appeal to stop drinking sauerkraut juice or to stop doing anything else that benefits one's health. This article is a playful demonstration that moral behavior in one domain gives one a license to do something immoral in another domain. Moreover, this is the first article that demonstrates that consumption of a healthy product also gives one a license to do something immoral.

\section{Acknowledgements}

We are grateful to Marc Bratschi, Jean-Luc Cueni, Florian Fankhauser, Christine Lötscher and Barbara Moser. They conducted the research for their Bachelor's theses, which were submitted to the University of Bern. 


\section{References}

American Psychological Association (2002). Ethical Principles of Psychologists and Code of Conduct. American Psychologist, 57, 1060-1073. http://dx.doi.org/10.1037/0003-066X.57.12.1060

Brown, R. C. H. (2013). Moral Responsibility for (Un)Healthy Behaviour. Journal of Medical Ethics, 39, 695-698. http://dx.doi.org/10.1136/medethics-2012-100774

Chapman, H. A., Kim, D. A., Susskind, J. M., \& Anderson, A. K. (2009). In Bad Taste: Evidence for the Oral Origins of Moral Disgust. Science, 323, 1222-1226. http://dx.doi.org/10.1126/science.1165565

Effron, D. A., Cameron, J. S., \& Monin, B. (2009). Endorsing Obama Licenses Favoring Whites. Journal of Experimental Social Psychology, 45, 590-593. http://dx.doi.org/10.1016/j.jesp.2009.02.001

Eskine, K. J., Kacinik, N. A., \& Prinz, J. J. (2011). A Bad Taste in the Mouth: Gustatory Disgust Influences Moral Judgment. Psychological Science, 22, 295-299. http://dx.doi.org/10.1177/0956797611398497

Eskine, K. J., Kacinik, N. A., \& Webster, G. D. (2012). The Bitter Truth about Morality: Virtue, Not Vice, Makes a Bland Beverage Taste Nice. PLOS One, 7. http://dx.doi.org/10.1371/journal.pone.0041159

Esses, V. M., Haddock, G., \& Zanna, M. P. (1994). The Role of Mood in the Expression of Intergroup Stereotypes. In M. P. Zanna, \& J. M. Olson (Eds.), The Psychology of Prejudice: The Ontario Symposium, Volume 7 (pp. 77-101). Hillsdale, NJ: Lawrence Erlbaum Associates.

Finkelstein, S. R., \& Fishbach, A. (2010). When Healthy Food Makes you Hungry. Journal of Consumer Research, 37, 357367. http://dx.doi.org/10.1086/652248

Forgas, J. P. (1995). Mood and Judgment: The Affect Infusion Model (AIM). Psychological Bulletin, 117, 39-66. http://dx.doi.org/10.1037/0033-2909.117.1.39

Hagger, M. S., Wood, C., Stiff, C., \& Chatzisarantis, N. L. D. (2010). Ego Depletion and the Strength Model of Self-Control: A Meta-Analysis. Psychological Bulletin, 136, 495-525. http://dx.doi.org/10.1037/a0019486

Hayes, A. F. (2013). Introduction to Mediation, Moderation, and Conditional Process Analysis: A Regression-Based Approach. New York: Guilford Press.

Jordan, J., Mullen, E., \& Murnighan, J. K. (2011). Striving for the Moral Self: The Effects of Recalling Past Moral Actions on Future Moral Behavior. Personality and Social Psychology Bulletin, 37, 701-713.

http://dx.doi.org/10.1177/0146167211400208

Kantonale Ethikkommission Bern (2011). Bundesgesetz über die Forschung am Menschen. http://www.admin.ch/opc/de/official-compilation/2013/3215.pdf

Khan, U., \& Dhar, R. (2006). Licensing Effect in Consumer Choice. Journal of Marketing Research, 43, 259-266. http://dx.doi.org/10.1509/jmkr.43.2.259

Mazar, N., \& Zhong, C. B. (2010). Do Green Products Make Us Better People? Psychological Science, 21, 494-498. http://dx.doi.org/10.1177/0956797610363538

Merritt, A. C, Effron, D. A., \& Monin, B. (2010). Moral Self-Licensing: When Being Good Frees Us to Be Bad. Social and Personality Psychology Compass, 4, 344-357. http://dx.doi.org/10.1111/j.1751-9004.2010.00263.x

Miller, D. T., \& Effron, D. A. (2010). Psychological License: When It Is Needed and How It Functions. Advances in Experimental Social Psychology, 43, 115-155. http://dx.doi.org/10.1016/S0065-2601(10)43003-8

Monin, B., \& Miller, D. T. (2001). Moral Credentials and the Expression of Prejudice. Journal of Personality and Social Psychology, 81, 33-43. http://dx.doi.org/10.1037/0022-3514.81.1.33

Oakes, M. E., \& Slotterback, C. S. (2004). Prejudgments of Those Who Eat a "Healthy" versus an "Unhealthy” Food for Breakfast. Current Psychology, 23, 267-278. http://dx.doi.org/10.1007/s12144-004-1001-6

Stein, R. I., \& Nemeroff, C. J. (1995). Moral Overtones of Food: Judgments of Others Based on What They Eat. Personality and Social Psychology Bulletin, 21, 480-490. http://dx.doi.org/10.1177/0146167295215006

Vartanian, L. R., Herman, C. P., \& Polivy, J. (2007). Consumption Stereotypes and Impression Management: How You Are What You Eat. Appetite, 48, 265-277. http://dx.doi.org/10.1016/j.appet.2006.10.008

Weibel, C., Messner, C., \& Brügger, A. (2014). Completed Egoism and Intended Altruism Boost Healthy Food Choices. Appetite, 77, 38-45. http://dx.doi.org/10.1016/j.appet.2014.02.010 